\title{
DEL CLASICISMO FRANCÉS A LA CRÍTICA CONTEMPORÁNEA HISTORIA DE LAS IDEAS LITERARIAS (I)*
}

Alicia Yllera

UNED

\section{El CLASICISMO FRANCÉS Y EL SIGLO XVIII}

\subsection{EI apogeo del clasicismo francés: «L'Art poétique» de Boileau (1674)}

Durante la primera mitad del siglo XVII se abren progresivamente camino en Francia las teorias preceptivas venidas de Italia. Guez de Balzac y Jean Chapelain, entre otros, simbolizan el esfuerzo de los «doctos» por extender unas teorías que, hasta finales de los años treinta, sólo tienen una repercusión limitada en el mundo de la creación literaria. Desde principios de siglo, Malherbe, con su Commentaire sur Desportes, ha inaugurado un tipo de crítica que tiende no ya a buscar las bellezas de la obra sino a destacar los defectos de detalle, especialmente las incorrecciones lingüisticas. Proscribe los términos dialectales, frecuentes en los autores del siglo anterior, impone la estricta sujeción al habla parisiense, la composición de obras comprensibles para un público cortesano, con lo que quedan excluidas las metáforas barrocas. La creación de la Academia francesa (1637) supone la aparición de un cuerpo con autoridad reconocida en materia de lengua y de literatura. Apenas creada, ha de dirimir en el espinoso asunto de la Querelle $d u$ "Cid» de Corneille. Los adversarios de Corneille han recabado su

* Este artículo constituye la primera parte de esta breve visión de las ideas literarias desde la segunda mitad del $x$ vil hasta hoy. La segunda parte se publicará en el próximo número de esta misma revista. En ella figurarán todas las referencias bibliográficas. Este trabajo debía servir de introducción a un manual, realizado en colaboración, de crítica literaria y teoría de la literatura. 
autoridad. Recae sobre Chapelain la tarea de elaborar el juicio de la Compañía y el escritor se ve en el dilema de elegir entre aceptar una obra que el público ha aplaudido con entusiasmo y descontentar a los doctos, que la juzgan irregular, o desautorizar el éxito popular. Intenta una solución intermedia con una tenue critica que reelaborará, endureciéndola, por exigencias de Richelieu. Con los Sentiments de l'Académie française sur la tragicomédie du «Cid» (1638) se crea el precedente de enjuiciar una obra por su sumisión a los cánones preceptistas y morales. A partir de este momento pierde importancia el teatro irregular. El triunfo del preceptismo en el teatro, género de importancia inigualable en este momento, inicia el período de predominio del clasicismo en Francia.

No hay que olvidar, sin embargo, que la estricta ortodoxia clásica fue muchas veces más un ideal reclamado por los críticos que una realidad en la práctica de los autores. El preceptismo exigía, como primer principio, el fin didáctico de la obra. La mayoría de los autores aceptaron esta exigencia, al menos en teoría, pero Molière declara que el fin que se propone en sus comedias es, sencillamente, divertir al público. Por otra parte, este movimiento preceptista francés no se apoyó en una reflexión original sobre las doctrinas de la antigüedad. R. Bray comprobaba la escasez de ediciones y de traducciones francesas de la Poética de Aristóteles': los preceptistas franceses se inspiraron en general en los comentaristas italianos del Renacimiento (especialmente en Vida, Escaligero y Castelvetro).

Del mismo modo que en Italia, las teorías de Aristóteles se presentan en Francia fundidas con las de Horacio, pensando que el autor latino se había inspirado en el griego. De Horacio tomaron la concepción didáctica de la literatura, a la que se consideró como una rama de la filosofía moral. Se creía en el carácter absoluto e inalterable de la belleza, idéntica a pesar de los cambios históricos y sociales, con lo que se imponía la imitación de los antiguos, ya que éstos habían hecho la mejor imitación posible de la naturaleza, fin último del arte. Pero, concebir el arte como una imitación de la naturaleza (teoria de la mimesis) no supone que impere una noción realista de éste pues se piensa que el arte debe seleccionar y superar a la naturaleza, ya que es superior a ésta, como la ficción es superior a la historia, al dar cabida únicamente a cuanto es bello y bueno. Junto a la imitación de la naturaleza y de la antigüedad, los dos grandes pilares de la crítica clásica son la exigencia de verosimilitud y de decoro. La verosimilitud es un viejo concepto aristotélico que originariamente buscaba ampliar las posibilidades del poeta, permitiéndole presentar fábulas verdaderas o verosimiles (creibles). Aunque no existe una noción unívoca de verosimilitud en el clasicismo francés, en líneas generales designa lo que es aceptable y creible

\footnotetext{
' Una edición francesa y dos traducciones a lo largo de los siglos xVı y xvıl (p. 49).
} 
para el público contemporáneo. El decoro, noción de procedencia horaciana, presentaba un carácter más moral y exigia someterse a las convenciones morales de la época (Chimène, en el Cid de Corneille, falta al decoro al aceptar al asesino de su padre como esposo), pero contenia también cierta noción social (exigía adecuar la conducta del personaje a la clase social a la que pertenecía) y estética (impedía toda ruptura de carácter del personaje). Para imponer estas normas los preceptistas franceses apelan a la autoridad de los antiguos pero sobre todo a la razón, que aconseja imitar a la naturaleza y seguir las mejores obras del pasado. Sostienen que el valor de las normas antiguas procede de que se basan en la razón. Aristóteles y Horacio describieron cuantos géneros podían cumplir adecuadamente los fines didácticos de la literatura y formularon unas reglas válidas para todas las épocas porque se apoyan en la razón universal. Quedan descartados todos los nuevos géneros (lo que los críticos italianos habian discutido un siglo antes): no se acepta que los cambios históricos puedan alterar los cánones de belleza.

Los preceptistas de las últimas décadas del siglo insisten particularmente en que la razón es la justificación última de sus normas y en que los preceptos de los antiguos son válidos por apoyarse en ella. No es extraña esta insistencia en la razón como base de los preceptos poéticos después de que Descartes rechazase el principio de autoridad como fundamento filosófico, difundiese la hostilidad a la tradición y desdeñase, de este modo, el estudio de la historia y de las lenguas clásicas. A finales del siglo, Pierre Bayle, protestante francés exiliado en Holanda por la Revocación del Edicto de Nantes (1685), muestra, en su Dictionnaire historique et critique (1695-1697), las atrocidades, fábulas y puerilidades sobre las que se asienta el prestigio de los antiguos.

A partir de 1637 se publican en Francia numerosos tratados teóricos generales o sobre géneros concretos. Hasta entonces las discusiones teóricas quedaban reservadas a los prefacios de las ediciones de obras dramáticas, en las que se hacían declaraciones a favor o en contra de las reglas según la índole de la pieza publicada. La Poétique (1639) de La Mesnadière inicia, tardíamente con respecto a otros países, la serie de tratados. Años después, el abate d'Aubignac publica su Pratique du théatre (1657), en la que analiza las obras contemporáneas y declara asentar sus principios sobre la razón. El P. Le Bossu elabora su Traité du Poème épique (1675), legislando sobre el género considerado más elevado en la época. Un año antes habían aparecido dos tratados generales, uno de los cuales se convertiría en modelo del preceptismo francés: Les Réflexions sur la "Poétique» d'Aristote et sur les ouvrages des poètes anciens et modernes (1674) del P. Rapin y L'Art poétique (1674) de Boileau. El tratado de Boileau conoció un éxito enorme. No era, sin embargo, su autor un hombre de gran sentido estético ni un gran innovador. Se limitaba a resumir las teorías más extendidas en su momento, con grandes dosis de sentido común. Contribuyó a su éxito su ex- 
presión sencilla, la brevedad y rotundidad de su obra y su exposición en verso. Boileau es categórico en sus afirmaciones. Acierta al condenar los pésimos poemas épicos de su época, pero juzga según el ideal de lengua de su momento, lo que le lleva a rechazar toda la poesía del XVI incluyendo a Ronsard. Desdeña toda la literatura extranjera, como es frecuente en estos años en Francia, con alguna excepción como Saint-Evremond, a quien su largo exilio en Inglaterra permitió juzgar la literatura de su época con espíritu más abierto.

No todos compartían, sin embargo, la fe ciega de Boileau en la superioridad de la antigüedad. Así se vio en la Querelle des Anciens et des Modernes (1687-1697), polémica a la que tal vez se haya concedido una importancia excesiva. Polémicas análogas habían surgido en otros países: Italia conoció varias a lo largo del Xvi (especialmente, las del Ariosto, el Tasso, el Pastor Fido de Guarini, etc.), en las que se ensayaron los argumentos esgrimidos en la polémica francesa, como años antes los partidarios y adversarios del $C i d$ de Corneille habían utilizado argumentos presentados en la Querella del "Pastor Fido" de Guarini. Charles Perrault suscitó la Querelle des Anciens et des Modernes con su Poème du Siècle de Louis le Grand, leído ante la Academia en 1687. Su objetivo no era rebajar la grandeza de los antiguos sino exaltar los logros artísticos y científicos del reinado de Luis XIV. Frente a los "antiguos» (Boileau, La Fontaine, Racine, etc.) se constituyó el clan de los «Modernos»: algunas de las posturas de estos últimos anuncian tímidamente las del XVIII, sobre todo su noción de progreso y su concepción más relativista del arte y de las letras: así, Fontenelle, activo partidario de los «Modernos», elabora, probablemente por vez primera, la teoría de la influencia del clima sobre la literatura y las artes (Digression sur les Anciens et les Modernes, 1688), que más tarde Montesquieu aplicará a la legislación: con ello se atentaba contra el principio de universalidad de la belleza y de los juicios críticos y se abría la puerta a la crítica subjetiva y sensualista que aparecerá en el siglo siguiente.

El preceptismo clásico se prolonga en Francia en el siglo XVIII pero, tras estos principios generales, que se suponen apoyados en la razón, se abre camino una concepción subjetiva y sensualista de la belleza, basada en la impresión agradable que produce el objeto artístico en el espectador o lector. La creación literaria se aparta mucho más que la creación teórica del modelo del siglo anterior, lo que acentúa el foso entre teoría y práctica literaria.

En 1711, el P. André publica su Essai sur le Beau, en el que define tres tipos de belleza: una esencial e independiente de toda institución, otra natural pero también independiente de las opiniones diversas de los hombres y una tercera sometida al genio de las lenguas, al gusto de los diversos pueblos, etc. Con ello acepta la universalidad de la belleza sostenida en el XVII pero intenta compaginarla con las teorías relativistas del XVIII. Las cualidades de la belleza son el orden, la regularidad, la proporción y la simetría. La razón y la reflexión son los criterios de la belleza y existe un 
gusto certero grabado en la naturaleza humana general. Unos años después, Crousaz volvería sobre el tema (Traité du Beau, 1724).

Con las Réflexions critiques sur la poésie et la peinture (1619) del abate Du Bos, el sentimiento ocupa ya un lugar destacado como juez del arte. Plantea las causas del progreso y decadencia de las artes, desaparece la noción de universalidad de la belleza y se destaca la influencia sobre el genio del medio, de la época, etc.

El abate Batteux intenta construir una teoría general de las artes (Traité des Beaux-Arts, réduits à un seul principe, 1746), aceptando para todas ellas un único principio: la imitación de la belleza y bondad en la naturaleza, de la naturaleza en su mayor perfección. Reconoce el papel del gusto al valorar una obra de arte pero piensa que se apoya siempre en un juicio previo. Imperan en él los principios del siglo anterior aunque con menos dogmatismo: es menos tajante que Boileau en la exigencia de las unidades dramáticas, por ejemplo.

Voltaire es un admirador del arte de la época de Luis XIV y del preceptismo que permitió tan extraordinario florecimiento artistico y literario. Pero, sobre todo en su etapa juvenil, no es un neoclásico inflexible: intuyó el genio de Shakespeare, aunque lamentó que ignorase las reglas. Pensaba que el gusto primaba sobre las reglas al enjuiciar la creación artística, aunque creía en la existencia de un gusto universal. No expuso su pensamiento teórico de modo sistemático, ni intentó innovar en este dominio. Incluso en sus años de vejez volvió sus ojos con mayor nostalgia hacia el pasado, convencido del mal gusto que reinaba en su país en ese momento y se aferró con mayor ahínco a su credo neoclásico.

En cambio Diderot, a pesar del aspecto contradictorio de muchas de sus ideas y de su carácter asistemático, contribuyó mucho más que Voltaire a renovar las teorias literarias y artísticas de su momento, aunque sin romper totalmente con los presupuestos neoclásicos, sobre todo en sus últimos años. La proliferación de revistas que hablaban de obras extranjeras había introducido, de hecho, cierto cosmopolitismo en Francia y contribuido a resquebrajar el férreo principio de la absoluta superioridad artística de la época de Luis XIV. Diderot participa de este espíritu. Su teoría del arte es esencialmente sentimental. El arte ha de conmover. Aboga por una literatura patética. Piensa que el arte debe imitar a la naturaleza y admira a los antiguos pero, hombre de su tiempo, exalta la novela sentimental de Richardson. Desea renovar el teatro francés y recurre para ello al empleo de temas contemporáneos: crea así en Francia el drama burgués, al que defiende en escritos teóricos que acompañan a sus piezas Le Fils naturel (1757) o Le Père de famille (1758). Sus opiniones teóricas tienen hoy un interés meramente histórico: carecen de grandes vuelos y con frecuencia se inspiran en críticos ingleses. Piensa que el teatro ha de ser escuela de rectitud y pone en escena no a caracteres sino a condiciones o estados sociales. La parte más interesante de su obra crítica está contenida en sus Salons. En estas 
críticas de arte expone su concepción del genio como una especie de enfermedad sagrada. Hay ciertos ecos, en sus teorias, del idealismo platónico: cree en el carácter absoluto de la belleza que se eleva por encima de los condicionamientos históricos. Como expone en el Paradoxe du comédien, el arte es un mundo autónomo con respecto a la realidad y posee sus leyes propias: así, el mejor actor no es el más sensible ni el que más se identifica con sus personajes, sino el más frío y capaz de permanecer indiferente a todos ellos. Como Vico, cree que el genio florece más en los pueblos bárbaros que en los civilizados porque, al ser más espontáneos y apasionados, están mejor dotados para la poesía.

Diderot gozó de gran prestigio en Alemania. Fue amigo de F. M. Grimm e influyó sobre Lessing.

Diderot deseaba crear un teatro nuevo y adaptado a su tiempo. Dentro de esta misma tendencia, Sebastián Mercier (1740-1814) compuso obras de carácter sentimental y moralizante, que contaron con un éxito popular momentáneo. En Du Théatre, ou nouvel essai sur l'art dramatique (1773) rechaza el teatro clásico francés, salvo Molière por inspirarse en la antigüedad, cosiderándolo obra libresca, trasplantado del de la vieja Grecia y ajeno a la vida de su tiempo.

Pese a autores como Mercier, la crítica francesa de la época seguía apegada, en su mayoría, a la corriente neoclásica. La Harpe (1739-1803), en sus conferencias en el Liceo de París, defiende el teatro clásico y sobre todo el de Racine y Voltaire. Las publica bajo el título ambicioso de Cours de littérature ancienne et moderne (1799) pero este primer intento de historia literaria en Francia queda limitado al mundo clásico y a la literatura francesa de los siglos XVII y XVIII.

Diversas obras anunciaban la renovación prerromántica y romántica, al proclamar una concepción sentimental y emotiva de la literatura que no triunfará en Francia hasta 1830. La Revolución supuso cierta vuelta a la antigüedad y con Napoleón el clasicismo, considerado el arte nacional por excelencia, se impuso como arte oficial.

\subsection{El neoclasicismo inglés}

En los demás países europeos, el prestigio de las letras francesas de la época de Luis XIV influye, con mayor o menor fortuna, en el triunfo de las teorías neoclásicas. En Inglaterra esta influencia es perceptible a partir de la segunda mitad del XVII. John Dryden (1631-1700) compone tragedias clásicas, poesías heroicas y líricas, sátiras, etc., y diversas obras teóricas, esencialmente su Essay of Dramatic Poesy (1668), compuesto en forma de diálogo, en el que se pronuncia por la regularidad del teatro francés, aunque 
comprendiendo y exaltando, a diferencia de Rymer (1641-1713), la grandeza de Shakespeare. Johnson lo consideraría como el padre de la crítica inglesa.

Inspirándose en Aristóteles, Horacio y Boileau, Alexander Pope (16881744) compone su Essay on Criticism (1711), en el que recomienda a los poetas imitar a la naturaleza y a los antiguos, y observar las reglas, ya que éstas permiten imitar mejor a la naturaleza y que imitar a los antiguos es imitar a la naturaleza. Esto no le impide, como a muchos otros críticos neoclásicos ingleses, reconocer el genio de Shakespeare, lo que confiere a la crítica inglesa un carácter menos dogmático que el de Boileau.

Samuel Johnson (1708-1784) es también neoclásico sin por ello aceptar fielmente las teorias de Boileau. Utiliza como gran principio crítico la moralidad de la obra: pide que la literatura refleje la vida y sea verdadera, pero buscando en la realidad lo general y no lo particular. Sólo acepta las reglas que se basan en la naturaleza y no las que no tienen más justificación que la autoridad de los antiguos. Al no conceder a las unidades el carácter obligatorio que tienen para la mayoria de los autores neoclásicos puede apreciar el genio de Shakespeare, sin reprocharle las libertades que toma con ellas. Ve en él, esencialmente, un gran pintor de la vida.

La filosofia predominante en Inglaterra es el empirismo, esencialmente el empirismo de Locke, que concede escasa atención al sentimiento. Mayor atención le dedica la escuela escocesa, interesada además por diversos aspectos de la vida psicológica, lo que abre caminos nuevos a la crítica literaria.

No hubo grandes contribuciones inglesas a la crítica literaria. Su principal contribución estuvo en las obras literarias que extendieron por el Continente el gusto por la literatura sentimental pero también en diversos tratados filosóficos sobre lo bello (lo que luego se denominaría estética) y en los inicios de la historia literaria. Francis Hutcheson (1664-1746), discípulo de Shaftesbury, compuso el primer tratado de estética inglés (Inquiry into the Origin of our Ideas of Beauty and Virtue..., 1725). David Hume (17111776), Edmund Burke (1729-1797) y Alexander Gerard discutieron el fundamento de la belleza y del gusto. Favorecieron el desarrollo del historicismo, del interés por la historia de la literatura, la concepción relativista del arte, al que comienza a considerarse en dependencia con el clima, el medio ambiente o las condiciones políticas del país, y la creencia (presente también en Vico y que tanto contribuyó a extender Rousseau) en la superioridad poética de las épocas primitivas. Esto suscitó el interés por la literatura de los pueblos considerados primitivos: tanto de los griegos homéricos como de la India o la Inglaterra primitiva. Más tarde los alemanes perfeccionaron la historia literaria. 


\subsection{Vico y la crítica literaria italiana del siglo XVIII}

En la primera mitad del siglo, Giambattista Vico (1608-1744) elabora su personal teoría sobre el origen de la lengua, de la humanidad y del arte, que expone en la Scienzia Nuova (1725). Rompe tajantemente con la concepción racionalista de la poesía que predominaba en su época, al identificarla con la imaginación y el mito. Las edades primitivas son las más aptas para las grandes composiciones poéticas, mientras que las épocas modernas sólo producen obras retóricas. Sus teorías quedaron sin influencia hasta que, a principios del xx, Croce las retomó en su Estética.

Diversos autores compusieron tratados neoclásicos en Italia: Della ragione poetica (1708) de Gian Vicenzo Gravina y Della perfetta poesia italiana... de Ludovico Antonio Muratori (1672-1750).

\subsection{La crítica literaria en España}

En la primera mitad del siglo XVIII destaca, sobre todo, Ignacio de Luzán (1707-1754). Publicó en 1737 una extensa Poética en prosa, de la que se haría, después de su muerte, una edición muy aumentada (1783), con numerosas adiciones y correcciones. Pese a que mucho tiempo se le consideró un imitador de los preceptistas franceses, Luzán pasó en Italia sus años de formación y alli se interesó por las cuestiones literarias. No es extraño que, en su Poética, las fuentes italianas sean más frecuentes que las francesas, aunque también utiliza a críticos franceses, como el P. Le Bossu para el poema épico, los escritos teóricos de Corneille sobre el teatro o el tratado sobre la belleza de Crousaz, etc. Sin embargo, como demostró Sebold, sus fuentes principales son grecolatinas: Aristóteles es el autor más citado. Hombre de enorme erudición, utiliza también a preceptistas españoles de los siglos XVI y XVII (González de Salas, Cascales, etc.) ${ }^{2}$.

Escribe movido por el afán de renovar las letras españolas y de servir de guía a los escritores. Su obra es uno de los tratados más completos de su época. Trata cuantas cuestiones se relacionan con la literatura. En los cuatro libros que componen su tratado, considera el origen y la esencia de la literatura, su utilidad y deleite, la poesía dramática y la epopeya. No

${ }^{2}$ Entre la primera y la segunda edición existe un considerable aumento de las referencias a críticos españoles, como también a la literatura española. Así, en la primera edición no cita al Pinciano, que cuenta con cinco referencias en la segunda, etc. Según ha demostrado Sebold, en la primera edición las referencias a preceptistas clásicos son cuatro veces más numerosas que las referencias a teóricos franceses y dos más que a críticos italianos. En la segunda edición las referencias a críticos españoles son más numerosas que las referencias a críticos franceses. 
dedica un libro especial a la lírica ya que considera que su definición está incluida dentro de la definición de la poesía en general.

No desea oponerse frontalmente a los partidarios del teatro español, por lo que se muestra conciliador en el Prólogo, aludiendo a los méritos, ingenio y aciertos de Calderón y Solís, aunque lamenta, más tarde, que estos autores, como también Lope de Vega, no «hubieran a sus naturales elevados talentos unido el estudio y arte» (p. 65). No condena, sin embargo, los autos sacramentales, a los que considera libres de la mayor parte de las reglas de la tragedia por su carácter alegórico. Su tono moderado difiere de los duros ataques posteriores de Blas Nasarre (1749) y otros. En poesía censura particularmente a Góngora, mientras que considera "excelente» a Fray Luis de León y alaba a Garcilaso, Herrera y Lupercio Leonardo de Argensola, etc. Entre la primera y la segunda edición de su obra amplía considerablemente sus conocimientos de la literatura española: numerosas adiciones de la edición póstuma contienen referencias a escritores o preceptistas españoles y esboza incluso, en esta edición, una historia de las letras españolas.

Sus principios son comunes a toda la corriente neoclásica: piensa que el arte requiere la unión del ingenio y del talento natural con el estudio y la observación de los preceptos que se apoyan en la razón universal y en la autoridad de los antiguos. Aunque reconoce que el clima, las costumbres, los genios, la educación, etc. influyen de ordinario en el estilo de una nación u otra - como ya reconocieron los griegos-, piensa que los preceptos de la poética son universales, por lo que no cabe sostener que las preceptivas clásicas son inadecuadas para el teatro español. La literatura, como la filosofia moral, tiene un fin didáctico y es una imitación en verso de la naturaleza, mejorándola. La poesía es pintura de los oídos y la pintura poesía de los ojos. La poesía dramática es, para el autor, más importante que la épica. Es partidario resuelto de las unidades dramáticas y, llevando a sus últimas consecuencias el principio de verosimilitud sobre el que se basa la unidad de tiempo, piensa que la acción de una tragedia o una comedia debe durar cuanto dura la representación o, a lo sumo, una o dos horas más, puesto que el público no mide exactamente el tiempo de la representación. Buscando también la verosimilitud rechaza toda obra dramática enteramente musical, es decir, la ópera (que sustituye, además, el deleite racional del teatro por el goce de los sentidos) y el uso de lo maravilloso pagano (dioses) en epopeyas modernas: con ello contradice a Boileau y critica en este aspecto a Camoens. No acepta los géneros híbridos, como la tragicomedia, y reprueba la licencia defendida por Corneille de las comedias heroicas, es decir, obras dramáticas con final feliz, como la comedia, y personajes propios de la tragedia (reyes y príncipes). Desea aplicar coherentemente los principios neoclásicos pero esto no le impide estar atento a las nuevas teorías de su momento. Da cabida, por ejemplo, al tratar del poema épico, a la teoría del «doctísimo» Vico; los primeros héroes fueron hombres 
rudos y fieros, como aparecen en Homero, pero el cambio de las costumbres, con el paso del tiempo, transformó la noción de héroe (p. 449).

Durante el reinado de Carlos III se favorece oficialmente el arte neoclásico. La polémica sobre los autos sacramentales se salda con su prohibición en 1765: habían encontrado adversarios tan rotundos como José Clavijo y Fajardo (1762) o Nicolás Fernández de Moratín (1762), que pedían su desaparición. Se clamaba también contra la irregularidad del teatro. Por estos años Tomás Iriarte traduce la Epistola de los Pisones de Horacio; se reimprime la Poética de Aristóteles (1778, 1798); se hicieron dos traducciones del Arte poético de Boileau (1787, 1807). A la influencia clásica y francesa se sumó la influencia inglesa y se tradujo también la poética de Hugh Blair, que tuvo gran éxito, y el Treatise on the Sublime de Edmund Burke, etc.

Paralelamente se desarrolló el interés por los orígenes de la literatura española. Tomás Antonio Sánchez publicó, entre 1779 y 1790, su Colección de poesias castellanas anteriores al siglo $\mathrm{XV}$, y unos años antes Luis José Velázquez había dado a la estampa sus Origenes de la poesía castellana (1754).

En la reflexión filosófica sobre la belleza destaca la obra de Esteban de Arteaga (1747-1799), jesuita expulsado de España que dejaría la Orden en Italia, La Belleza ideal (Investigaciones filosóficas sobre la belleza ideal), Madrid, 1789. A pesar del título de su obra, Arteaga no es un neoplatónico sino un discípulo de Locke y Condillac; la belleza ideal es una abstracción elaborada por el entendimiento a partir de los datos de los sentidos: es el modelo mental de perfección que el artista aplica a su creación, entendiendo por perfección lo que, imitado por las artes, es capaz de crear la imagen, ideal o afecto buscado por el artista según el fin y el instrumento. Su teoría de la belleza ideal se basa, pues, en la imitación, como es usual en las teorias preceptistas de la época. El fin del arte es imitar la naturaleza con el instrumento que le es propio y que, en el caso de la poesía, es el metro, como en el de la escultura es el mármol o el bronce. Pero la imitación no es mera copia pues no intenta confundirse con el original (Fidias y Miguel Angel no pretenden hacer pasar sus estatuas por seres vivos). Aunque la imitación busca la belleza ideal, puede incluir lo feo, ya que lo feo no es lo que se considera asi en los objetos sino lo que no es capaz de producir la ilusión y el deleite que se busca. Si el incluir lo feo dentro del dominio del arte supone una superación de las preceptivas de su momento, niega además la distinción simplista entre el arte realista y el idealista, puesto que el arte es siempre ambas cosas a la vez y sólo existen diferencias de grado. Comprende la importancia del sentimiento y del acto de creación artística y de la manifestación del alma del creador en la obra, lo que anuncia las teorias que se impondrán en la época siguiente. Da muestra de amplitud de espíritu al defender a Velázquez, Ribera, Murillo o los pintores flamencos, atacados en su época por el aspecto naturalista de su pintura y su complacencia en 
reproducir lo feo. En esto se aparta de Winckelmann. Comprende la grandeza de Shakespeare, al que llama (el intérprete de la naturaleza», y en los dramaturgos españoles descubre mucha plata «a la vuelta de mucha escoria». Propuso incluso, al final de su obra, un plan para un estudio científico de las artes de imitación en el que se analizarian las causas intrínsecas y extrínsecas que gobiernan el desarrollo de las artes.

\subsection{La crítica alemana. La aparición de la estética}

La principal renovación de las teorías sobre el arte, en la Europa del siglo XVIII, vino de Alemania. Roto el vínculo con la literatura alemana antigua, sin obras autóctonas que sirvieran de modelo, la reflexión crítica precedió al renacer poético. Junto al neoclasicismo imperante, se constituyó progresivamente una nueva teoría literaria, más preocupada por las cuestiones generales que por los análisis concretos.

El nombre de estética surgió en Alemania en la primera mitad del siglo XVIII. Su inventor, Alexander Gottlieb Baumgarten (1714-1762), designaba con este término la "ciencia del conocimiento sensitivo", con lo que abarcaba un dominio más amplio que el de la actual estética o filosofia del arte.

Baumgarten no tuvo gran incidencia en el movimiento estético a emán subsiguiente. No ocurrió así con Johann Joachin Winckelmann (1717-1768), crítico de las artes, admirado por los poetas y críticos literarios (Herder, Goethe, W. Schlegel, etc.). Resucitó la estética neoplatónica y concibió la belleza como algo ideal que se manifestaba en la serenidad, en la tranquila grandeza y la noble sencillez de las obras griegas. Superó las estrechas interpretaciones neoclásicas y creó la visión idealizada del arte griego en detrimento del romano. Pero además aportó un sentido historicista al análisis de las obras de arte que influiría en los teóricos de la literatura posterior. Consideró que la escultura griega se componia de cuatro períodos: iniciación, apogeo, decadencia y muerte, concepción organicista de la historia de las artes que años después aparece aplicada a la historia de la lengua y de la literatura.

Gotthold Ephraim Lessing (1729-1781) es considerado como el primer gran crítico literario alemán. Dramaturgo, tratadista de la estética e incluso teólogo, especialmente en sus últimos años, interesa a la historia de la crítica literaria esencialmente por su obra Laocoonte $(1766)^{3}$. No es esta obra un tratado sistemático, sino un conjunto de reflexiones que intentan refutar las teorías de Spence y Caylus, que explicaban las obras literarias a partir de

\footnotetext{
${ }^{3}$ A ello pueden añadirse sus artículos en la Hamburgische Dramaturgie (1767-1768), en los que enjuicia las representaciones dramáticas del teatro de Hamburgo, etc.
} 
las artísticas, y en parte de la interpretación que del grupo escultórico alejandrino había dado Winckelmann. El núcleo de su obra es la refutación del viejo tópico horaciano ut pictura poesis («la poesía como pintura»), que tendía a vincular ambas artes, considerando a la pintura como una poesía muda y a la poesía como una pintura parlante. Lessing separa tajantemente los procedimientos y el objeto de las artes plásticas y de la poesía. Sólo presentan en común el producir el mismo efecto en el hombre pero difieren tanto en el objeto como en la manera de imitar la realidad. La pintura (y en general las artes plásticas) es arte espacial; lo que le es peculiar es, por lo tanto, representar cuerpos. La poesía es arte temporal, representa acciones. También la pintura puede representar acciones pero únicamente de modo alusivo, del mismo modo que la poesía representa (describe) a los cuerpos. Una misma imagen puede ser suscitada en nuestra imaginación por medio de signos arbitrarios (el lenguaje) y por medio de signos naturales (las artes plásticas) pero la suscitan de modo diferente. El pintor ha de elegir el momento único, el más fecundo, el que mejor permite el libre juego de la fantasía pero este momento único no es nunca el más extremo (por ejemplo, el de máximo dolor). Rechaza, de este modo, la explicación que Winckelmann daba del Laocoonte: si el artista atenuó sus gritos convirtiéndolos en suspiros y evitó representar el momento de máximo dolor del sacerdote, no es porque esto fuese indigno de la nobleza del alma griega, en contraposición con el grito de Laocoonte en la Eneida de Virgilio, sino porque la manifestación del máximo dolor deforma el rostro, dándole un aspecto repulsivo, y el artista ha de elegir un momento único, el más acorde con la belleza que intenta plasmar y los momentos más extremos, al dejar menos libertad a la imaginación, son menos sugestivos para el contemplador. Pese a lo que cree Winckelmann, el griego no rehuye las manifestaciones extremas del dolor, pues aparecen en su poesía, pero las evita en las artes plásticas.

La belleza material surge de la armonía de las diversas partes que la vista abarca en un momento en su conjunto. Por eso, sólo la pintura y las artes plásticas pueden imitar la belleza material. La poesía sólo puede dar la idea de la belleza corporal al presentarnos sus efectos, como Homero al describir la impresión que causa la belleza de Helena en el consejo de los ancianos de Troya, o transformarla en gracia pues «La gracia es la belleza en movimiento» (p. 216). Para describir, la poesía transforma en sucesión lo que es simultáneo: Homero lo intuyó y, al mostranos el carro de Juno, hace que Hebe lo componga ante nuestros ojos, etc.

Condena, de este modo, la pintura alegórica y la pintura histórica, así como la poesía descriptiva. Piensa que la descripción en poesía rompe la ilusión, elemento esencial de este arte. La belleza se consigue de modo distinto en las artes plásticas y en la poesía.

Lessing no es un romántico pero abrió la puerta a las teorías románticas posteriores. Inició en literatura la crítica global, orgánica, frente a la crítica de detalle que predominaba en el neoclasicismo francés. Admiraba el mundo 
griego pero miraba con ojos desdeñosos el neoclasicismo francés. Subvirtió muchos de los principios neoclásicos, como el de la creencia en una belleza única para todas las artes. Acepta incluso lo inverosímil si es capaz de crear una mayor belleza: contra toda verosimilitud el escultor presenta desnudo a Laocoonte, mientras que en Virgilio reviste sus ornamentos sacerdotales, pues el artista comprendió la mayor belleza del cuerpo, obra natural, frente al vestido, creación humana. La fiel imitación de la naturaleza se sacrifica también a la búsqueda de la mayor belleza. Además, mostró, indirectamente, cómo muchos principios neoclásicos se asentaban sobre una errónea interpretación de los antiguos, pues considera que los antiguos ya eran conscientes de las grandes diferencias que separan estas artes. El tópico ut pictura poesis se basaba en un malentendido.

Muchas de sus rotundas afirmaciones están hoy desfasadas pero la importancia histórica de su obra fue inmensa. Su teoría de las artes plásticas es más limitada que su teoría de la poesía. Era un literato y no vacilaba en proclamar la superioridad de la poesía sobre la pintura.

En los últimos años del siglo XVIII surgió en Alemania un movimiento de interés creciente por la estética. En buena medida estuvo suscitado por la renovación aportada por la Critica del juicio (1790) de Kant (1724-1804). Al separar Kant el arte de toda noción de utilidad y didactismo, dio autonomía al objeto de la estética, pero al mismo tiempo rehuyó el sensualismo que reduce el arte a mero placer. El juicio estético se diferencia de la percepción de lo útil, lo placentero, lo verdadero y lo bueno. El arte es producto del ingenio, don de la naturaleza, por lo que no puede aprenderse, ni heredarse, ni es susceptible de progreso.

El juicio estético es desinteresado pues está libre de todo interés sensual o racional (lo que lo distingue de lo agradable, que es placer sensual y no meramente contemplativo, y de lo útil, que supone una noción racional); es lo que agrada universalmente y sin concepto, pues no existe en él un consentimiento racional sino un asentimiento instintivo. Es una finalidad sin fin; es decir, una pura forma que tiene su fin en la misma representación.

Kant distinguió lo bello de lo sublime. Su teoría de lo sublime tendría gran repercusión posterior, especialmente en Schiller. La emoción de lo sublime es más poderosa que la de lo bello. Lo bello atrae siempre, infunde amor. Lo sublime puede también repeler e infunde en general respeto y admiración. Nada de lo que hay en la naturaleza es de por sí sublime, pues lo sublime es meramente subjetivo, reside en las ideas de razón, en nuestro mundo interior. Lo sublime supone la idea de infinito. Nuestra imaginación percibe lo sublime al enfrentarse con la inmensidad e infinitud del universo y de la naturaleza.

Lessing buscaba elaborar un nuevo clasicismo más auténtico, retornando al mundo griego y prescindiendo de las obras francesas. En la ge- 
neración siguiente Johann Gottfried Herder (1744-1803) supone ya una ruptura con el gusto neoclásico. Recibió influencias muy diversas. Se interesó por la poesía popular y nacional de los pueblos primitivos, en la que incluia el Antiguo Testamento, Homero, pero también al supuesto Ossian, al que admiraba como muchos de sus contemporáneos. Deseaba restaurar la literatura alemana. Trazó grandes síntesis de la historia literaria, en las que atendía a los factores externos que condicionan la literatura (clima, raza, costumbres, etc.) y sobre todo al «espíritu nacional». Desacreditó definitivamente en Alemania la poética francesa y preparó el interés subsiguiente por la poesía popular, nacional y primitiva. Influyó decisivamente sobre el joven Goethe y los románticos alemanes.

Goethe (1749-1834) aceptó en su juventud los ideales de naturalidad y expresividad de Herder. El viaje a Italia lo convirtió a los gustos clásicos. Cosmopolita, acuñó el término de «literatura universal». Reelaboró las nociones neoclásicas, compaginándolas con su idea inicial de la independencia del arte y de la libertad del poeta.

Friedrich Schiller (1759-1805) partió de los presupuestos kantianos, aunque posteriormente recibió la influencia de Fichte. Añadió a la oposición kantiana entre los imperativos de la razón, o deber, y los imperativos físicos a los que está sometido el hombre, un nuevo término, el estado estético, por el que logra armonizar su materia fisica y su ideal. La belleza es así la síntesis entre la realidad y lo ideal. El estado estético permite el paso entre el hombre sensitivo (estado físico) y el hombre en el estado lógico y moral. El artista se convierte en mediador entre el hombre y la naturaleza. El arte cobra en él una elevada misión civilizadora al reconstruir la totalidad de la esencia humana y reconciliarlo consigo mismo y con el mundo.

Rechaza el naturalismo. La verdad del arte se aparta de la realidad para abrazar el puro ideal. El artista toma de su tiempo la materia de su arte pero busca la forma en las edades más nobles e incluso en la esencia del arte. Conserva en lo principal los gustos neoclásicos pero prescindiendo de los aspectos externos de las reglas o del didactismo ingenuo que las acompañaba.

Elaboró una distinción entre la poesía ingenua o «natural», espontánea, y la poesía sentimental, reflexiva y consciente, la primera más frecuente en la antigüedad, la segunda en la época moderna. Más tarde los hermanos Schlegel darian un nuevo contenido a esta dualidad e intentarían definir la poesía clásica opuesta a la romántica.

\subsection{Visión general del siglo XVIII}

El siglo XVIII supone el triunfo del neoclasicismo en la mayoría de los países europeos. Se considera como objeto de la literatura la imitación de 
la naturaleza (mejorándola) y de los antiguos, que nos han dejado el mejor ejemplo de esta imitación. El genio artístico del poeta debe completarse con la observación de unos preceptos universales, basados en la razón. Bajo esta aparente uniformidad, la práctica literaria se disocia progresivamente de las teorias imperantes y se crea una literatura del sentimiento que prepara la subversión de los cánones estéticos que realizará la época siguiente. Paulatinamente se prepara el movimiento del que surgirá la renovación crítica del romanticismo. Pero en ningún momento se plantea en esta época una verdadera ruptura. A principios del siglo, Vico elabora en Italia una teoría basada en la creencia en la superioridad de los pueblos primitivos para la poesia. Nociones análogas aparecen en el romanticismo alemán pero esto no obsta para que se hagan eco de sus teorías representantes del neoclasicismo como Luzán. En Alemania se crea un poderoso movimiento de reflexión filosófica que da lugar al nacimiento de la estética como disciplina filosófica independiente. Kant la fundamenta al proclamar la autonomía de su objeto frente a las demás disciplinas. Con ello se resquebraja la vieja noción renacentista, heredada de la antigüedad, que consideraba a la literatura como parte de la filosofia moral.

En diversos países el movimiento preceptista intenta una más flexible interpretación de los principios del arte de lo que habían presentado los teóricos franceses de la segunda mitad del XVII y especialmente Boileau. Winckelmann reivindica en arte lo griego a expensas de lo romano y lo francés. Sobre todo, Lessing, perfectamente imbuido del espíritu neoclásico, intenta un retorno a la pura captación de la poesía y del arte griego, prescindiendo de una crítica de detalle. Diderot y sobre todo Herder anuncian una nueva era. Con Goethe y Schiller la herencia de Herder y de Kant se une a la más pura esencia del clasicismo. Los cambios son progresivos y mucho menos virulentos de lo que podría parecer. El XVIII ha destacado la importancia de la literatura del sentimiento, ha independizado la poesía de la subordinación a la moral, ha iniciado una concepción orgánica de la obra literaria, ha suscitado el interés por el origen de los pueblos y las formas literarias populares y primitivas y, al tomar en cuenta los cambios literarios y los factores que los explican, ha sentado las bases de la historia literaria. Sobre estos elementos dispersos se constituirán las teorías literarias de la primera mitad del siglo XIX.

\section{LA PRIMERA MITAD DEL SIGLO XIX: EL PERÍODO ROMÁNTICO, LA ESTÉTICA ALEMANA Y LA HISTORIA LITERARIA}

\subsection{El Romanticismo alemán. La estética alemana}

Friedrich Schlegel (1772-1829) forjó muchas de las nociones que más tarde daría a conocer su hermano. Tenía una muy elevada noción de la 
literatura, a' la que consideraba un elemento esencial en la vida y dignidad social de las naciones. Entendía la historia literaria como una ciencia filosófica; subordinaba la poesía a la filosofia y a la religión, sobre todo en la última etapa de su vida, después de su conversión al catolicismo. Se interesó en un principio por la literatura griega, aunque más tarde decreció este entusiasmo inicial. Contribuyó decisivamente a extender el interés por el sánscrito. Le atraía la literatura medieval aunque nunca poseyó grandes conocimientos en este dominio.

Partió de la noción de poesía sentimental de Schiller para elaborar su teoría de la poesía romántica. Difiere el sentido que da al término romántico del que suele tener en la actualidad. La poesía romántica es para él un género global, capaz de conectar la literatura con la filosofia. Pero no considera que su época sea esencialmente romántica y en cambio encuentra los mejores represenantes de esta tendencia en el Renacimiento o en la Edad Media. No existe en él oposición entre romántico y clásico, pues llama romántica a toda poesía en la que existe entusiasmo profético y sentimiento, e incluso tiende a identificarla con la poesía cristiana.

Era más original que su hermano August Wilhelm (1767-1845) quien, sin embargo, tuvo mucha más resonancia al reelaborar y divulgar conceptos anteriormente expuestos por él. No compartía August Wilhelm la inclinación al misticismo profético de su hermano. Como él se interesó por las literaturas antiguas y sobre todo por el sánscrito, por la cuestión de los géneros literarios y consideró como él que la épica era el gran género clásico mientras que la novela era el género romántico: es consciente de la filiación etimológica que vincula romantik a Roman («novela»). Su obra de mayor resonancia fueron sus Lecciones de literatura y arte dramático (1809-1811), lecciones impartidas en Viena y posteriormente publicadas. En ellas presenta su teoría de la tragedia y de la comedia: en la tragedia el hombre es juguete del destino, hasta llegar a comprender la caducidad de los placeres y afectos humanos; la comedia requiere desprenderse de toda idea triste para gozar sencillamente la felicidad del momento: para ello es necesario que los personajes cómicos sean presentados de manera que no podamos sentir ni compasión ni aversión por ellos. Pero su teoría más famosa es su contraposición entre romántico y clásico. Esta contraposición articula este primer intento de elaborar una historia del teatro occidental, desde los griegos hasta sus contemporáneos. Pese a su intento de alabar ambas tendencias por igual, se inclina por el arte romántico. Admira lo griego, aborrece lo francés y alaba a Calderón y a Shakespeare.

Friedrich Schelling (1775-1854), discípulo de Fichte, resalta el aspecto inconsciente del genio. En su sistema idealista, dedica al arte una atención superior a la que le concedían la mayoría de los filósofos de su época. Define la belleza como lo infinito presentado como finito. Piensa que un dia filosofia y poesía volverán a confluir, como en las épocas primitivas; entonces desaparecerá todo límite entre arte, filosofia, religión y mito. Proclama la 
total independencia del arte de todo fin ajeno a él mismo y justifica su absoluta negación del viejo principio de imitación de la naturaleza al declarar que los productos de la naturaleza no son necesariamente bellos.

Con los hermanos Grimm cobra particular importancia la atención a la poesía popular, de las naciones primitivas, la poesía "natural», opuesta a la "artística». Se considera que la poesía no ha hecho sino degenerar a partir de la época de las epopeyas. Se interesan por el pasado de las literaturas nacionales, por el folclore, aunque crean un foso entre la poesía popular y la poesía artística que hoy resulta inaceptable: en muchos casos la poesía popular no es sino formas de la poesía artística de las que el pueblo se adueña y perpetúa su memoria, alterándolas y recreándolas.

Diversos filósofos alemanes se interesaron por la teoría de las artes y la filosofia de la belleza.

Prescindiendo de otros pensadores, recordaremos la contribución de Friedrich Schleiermacher (1768-1834), teólogo luterano. Concebía el arte como autoexpresión, expresión y manifestación del artista. Elaboró la hermeneútica o ciencia de la interpretación. Piensa que lo esencial es la intuición que permite captar la obra artística como un todo. En ello consiste lo que define como círculo del entendimiento, es decir el detalle que sólo puede entenderse en función del todo. Además de esta intuición del alma del autor (método adivinatorio), preconiza un segundo método (comparativo), que consiste en analizar un texto por comparación con los demás textos del mismo autor o con la tradición literaria. Intentó, de este modo, elaborar una estética de la expresión.

En la filosofia de Hegel (1770-1831), el arte ocupa un importante lugar, sin por ello otorgarle el lugar supremo en las manifestaciones de lo absoluto, de la Idea, que ocupan, por encima de él, la religión y la filosofia.

Considera que en las obras de arte es donde los pueblos han expresado sus más intimos pensamientos y sus más ricas intuiciones. Rechaza como fin del arte la imitación, la expresión de la perfección moral, para admitir que su fin es representar lo bello. Lo bello es la unión de los dos términos que se ofrecen al pensamiento como separados y opuestos, lo ideal y lo real, la idea y la forma, etc. Defiende la superioridad del arte sobre la naturaleza puesto que el arte emana directamente del espíritu.

Puesto que para Hegel la Idea es el proceso histórico mismo y el ritmo dialéctico se manifiesta en él siempre bajo forma trilógica, toma la división del arte de los hermanos Schlegel (clásico y romántico) y le añade un tercer tipo, el arte simbólico, lo que le permite integrar, dentro de su esquema, el arte oriental. Mediante la forma simbólica, la Idea busca su verdadera expresión en el arte, sin lograr hallarla; con la forma clásica se realiza la armonía perfecta entre la Idea y su manifestación exterior. Su realización histórica se dio en el pueblo griego. En la forma romántica o arte cristiano se quiebra la bella unidad del ideal en busca de una armonía más profunda 
que el espiritu sólo encuentra en si mismo, mientras que antes lo buscaba en el mundo sensible.

Hegel expuso sus nociones de estética en unas lecciones que a su muerte fueron publicadas por su discípulo Hotho (Lecciones sobre la estética, 18351838). No presentan, pues, una forma definitiva. Se dividen en tres partes; la tercera, dedicada al sistema de las artes particulares, es la más importante.

A cada uno de los tres estadios descubiertos en la sucesión histórica de las artes corresponde también una de las artes particulares: al estadio simbólico, la arquitectura, al clásico, la escultura, al romántico, la pintura, la música y la poesía. Considera a la poesía el arte supremo por ser el más cercano al pensamiento. En ella distingue lo épico o lo objetivo, lo lírico o lo subjetivo y lo dramático, que supone la fusión de ambos (lo objetivo y lo subjetivo). Concede prioridad al arte dramático. La épica pertenece a las edades heroicas del pasado; en el mundo moderno encuentra un sustituto en la novela. Las diferentes artes están, además, en relación con el genio nacional y las diferentes disposiciones naturales de cada pueblo.

La influencia de Hegel suscitó el más extenso tratado de estética, compuesto por Friedrich Theodor Vischer (1807-1887) (Aesthetik... 6 vol., 18471858 ).

Entre los pensadores alemanes de la primera mitad del siglo XIX alcanzó resonancia, dentro de la teoría de la literatura, Arthur Schopenhauer (17881860). Su obra principal, El mundo como voluntad y representación, apareció en 1819, pero gozó de escasa difusión en ese momento y sólo hacia la mitad del siglo tuvo repercusión. Traslada a Occidente el nirvana budista. Considera la vida esencialmente dolorosa y el nirvana sólo alcanzable si se niega la voluntad de vivir. Su estética parte de Kant. Es decidido partidario de los clásicos frente a los románticos. Su teoría pesimista del arte cobra su mayor importancia con su teoría de la tragedia. La tragedia es escuela de resignación e incluso enseña a renunciar a la voluntad de vivir. A pesar de sus inclinaciones clasicistas, piensa que estos objetivos aparecen mucho más en la tragedia cristiana que en la tragedia griega.

Se elaboran en estos años las primeras historias de las literaturas nacionales: Georg Gottfried Gervinus (1805-1871) es el primer gran historiador literario alemán, autor de la mejor historia de la literatura anterior a Taine y De Sanctis. Concibe la historia literaria como parte de la historia en general, pues, para él, la literatura es expresión de la vida nacional de un pueblo.

\subsection{Inglaterra y E.E.U.U.}

En Inglaterra, sin producirse grandes rupturas, se transformó progresivamente la concepción de la poesía. Las innovaciones poéticas superaron 
con mucho las innovaciones criticas y no existió un poderoso movimiento estético como en Alemania. En buena medida, la filosofia imperante siguió siendo la de la escuela escocesa, caracterizada por su acentuado psicologismo y la ausencia de trasfondo metafísico de sus doctrinas.

Ejemplo de esta transición es Francis Jeffrey (1773-1850), crítico de gran influencia a través de la Edinburg Review $(1802 \rightarrow)$. Su crítica no es realmente romántica, sin ser tampoco neoclásica. Es hombre ecléctico, de gustos conservadores. Criticó la escuela lakista, aunque influyeron en estas críticas las diferencias ideológicas que lo separaban de sus miembros. No existe un trasfondo estético en su crítica; acepta el subjetivismo, pues considera que la belleza es subjetiva, y juzga a partir de sus gustos personales y de sus creencias morales. Su mayor admiración va para Shakespeare y su época. Es así un gran defensor de la tradición inglesa.

Suele considerarse a William Wordsworth (1770-1850) y a la escuela lakista la manifestación del Romanticismo inglés y la ruptura con el neoclasicismo anterior. Como crítico y teórico se caracteriza por su «emocionalismo", su concepción de la poesía como manifestación de sentimientos subjetivos, su exaltación de la sinceridad como uno de sus grandes valores (hasta alzarla a la categoría de norma estética), su creencia en la espontaneidad y cierta afición al primitivismo, y su rechazo del refinamiento de la civilización. El rasgo más característico de su concepción de la poesía es, sin embargo, su crítica de la cuidada dicción de la época anterior, su defensa del habla popular como materia poética, su conciencia de que la poesía puede encontrarse en las cosas más cotidianas y triviales. Desea transformar en materia poética todo cuanto constituye la materia de la vida.

Su concepción de la poesía desemboca en el prosaismo y en el didactismo pero, al mismo tiempo, era innovadora comparada con los principios neoclásicos.

El crítico inglés más destacado en estos años es Samuel Taylor Coleridge (1772-1834), que goza de gran prestigio en el mundo anglosajón. Es, sin embargo, mucho menos original de lo que podría parecer. Su gran interés reside en haber adaptado en su país la estética alemana y haber recogido la influencia de la poesía de esta nación. Sus teorias se inspiran en Kant, Schelling y Schlegel, aunque a veces combina las ideas alemanas con rasgos inspirados en el empirismo inglés, en la tradición psicológica e incluso con viejos resabios neoclásicos. Insiste en la unidad esencial de la obra de arte. En cuanto a las relaciones entre el arte y la naturaleza piensa que el arte imita a la naturaleza pero no a la naturaleza concreta sino a la universal y general, pues imitar no es meramente reproducir, copiar, lo imitado.

Carece del sentido histórico de los críticos románticos alemanes. Tampoco comparte su afición por el mundo medieval y permanece ajeno al movimiento erudito de su momento. Tiende a analizar a los autores prescindiendo de su momento histórico y se interesa esencialmente por la psi- 
cologia de' los personajes (como hace al considerar a Shakespeare), olvidando a veces las diferencias entre arte y vida.

En Thomas Carlyle (1795-1881) se detecta la influencia alemana. De ellos toma la noción de espíritu nacional que se manifiesta en la literatura de un país y la concepción de la obra literaria como una unidad, con identificación entre fondo y forma. Sentía recelos por la ficción y tendía a desplazar la crítica hacia la biografia y el didactismo, lo que combinaba con su misticismo crítico. También Thomas Babington Macaulay (1800-1859) se inclina con frecuencia por la biografia en su critica. John Ruskin (18191900) dedicó gran atención a la estética, más que ninguno de sus compatriotas, y expuso sus ideas, aunque de forma incoherente, en los tres primeros volúmenes de sus Modern Painters (1843-1856). Realizó una ingente labor a favor de las artes. Defendió la concepción organicista del arte del romanticismo. Aborrece el academismo y exalta la pintura prerrafaelina. Cree que el arte no puede ser mera copia de la naturaleza: el artista debe plasmar un tema que le embarga. Rechaza el realismo feo y vulgar y considera el arte como una actividad que perfecciona al hombre. Proust lo alabó, aunque luego lo censurase en parte.

Se realizan importantes esfuerzos en el terreno de la historia literaria y de la literatura anglosajona antigua: se estudia, después que en Dinamarca y Alemania, el Beowulf, las novelas caballerescas, las baladas y los cantos populares medievales; pero el interés se centra, sobre todo, en la época isabelina, aunque la historiografia inglesa no es comparable a la alemana o francesa.

Edgar Allan Poe (1809-1849) fue el primer crítico importante norteamericano. Influyó sobre Baudelaire, quien en parte deformó su figura. Limitó el didactismo imperante en la crítica de su país. Heredó del XviII su racionalismo y defendió la elaboración minuciosa de la obra literaria. Alabó la unidad de efecto de la obra y la brevedad que la favorecía. En cambio, su compatriota Ralph Waldo Emerson (1803-1882) defendió una concepción simbolista de la poesía y una noción de la misión del poeta de origen neoplatónico: el poeta es el profeta que transmite al hombre obras bellas que encarnan la Idea central del universo. El poeta descifra los símbolos contenidos en la naturaleza, pero el arte puede tratar todos los temas, la poesía puede surgir incluso a partir de hechos triviales. El genio es el ser pasivo que recibe la inspiración.

\subsection{Francia}

En Francia, el neoclasicismo se siente como arte especificamente nacional, de ahí que renazca con la Revolución y se convierta en "teoría oficial» 
con Napoleón. Hay que esperar su caída para que se abran camino otras tendencias. En esta renovación de las ideas sobre la literatura ocupa un lugar privilegiado Mme de Staël (Germaine Necker, 1766-1817). Su obra De la littérature considérée dans ses rapports avec les institutions sociales (1800) defiende una concepción de la poesía sensible y sentimental y destaca la repercusión que la literatura debe tener en el desarrollo de la sociedad. Se muestra heredera del XVIII, tanto por su fe en el progreso, como por su concepción sentimental de la literatura de influencia rousseauniana. Pero su obra de mayor repercusión fue De l'Allemagne (1813). La originalidad de sus teorías es escasa: adapta las Lecciones de A.W. Schlegel y como él contrapone una poesía clásica, antigua, a una poesía romántica y moderna. $\mathrm{Su}$ importancia radica esencialmente en haber suscitado el interés de los críticos y de los poetas franceses por la literatura de allende sus fronteras y en haber proclamado que el arte romántico es más adecuado al mundo contemporáneo que el arte clásico. Defiende, en lengua francesa, cierto cosmopolitismo que contrasta con la estrechez nacionalista de la mayoría de los críticos franceses de su momento. Permitió superar las fronteras e iniciar la concepción de los movimientos literarios como fenómenos europeos y no sólo vinculados a un país, y divulgó el término romántico. Diversas circunstancias contribuyeron al éxito de su obra, como el secuestro de la edición en 1810, lo que obligó a publicar la obra en 1813 en Inglaterra. Si su originalidad es muy escasa, la importancia histórica de su obra es, por el contrario, muy grande por la incidencia que tuvo en la renovación de la crítica y de la poesía en Francia y por la influencia que el romanticismo francés tuvo en los demás países románicos y en los países eslavos.

Chateaubriand (1768-1848) no desea romper con los modelos críticos neoclásicos del Antiguo Régimen pero aporta un nuevo sentimiento de la naturaleza y sobre todo su alabanza de las bellezas que trajo al arte el cristianismo (Le Génie du Christianisme, 1802). Además cree que el arte es manifestación del artista, que traslada a su obra rasgos de su vida personal. Exalta el genio pero, frente a estos rasgos prerrománticos, permaneció fiel, a lo largo de su vida, a su admiración por el clasicismo francés.

La batalla entre el romanticismo y el clasicismo se desarrolla en Francia en las décadas siguientes, sobre todo en los años 20. Interviene en ella Stendhal, recién llegado de Italia, que publica en 1823 su obra Racine et Shakespeare. Ataca las unidades dramáticas y define el romanticismo como lo que nos agrada hoy mientras que el clasicismo es lo que agradó a nuestros antepasados. Lo romántico es, de este modo, lo moderno. Stendhal se adelantó a los grandes manifiestos románticos franceses pero su influencia fue limitada. Por esos años el clan romántico se define como monárquico y conservador mientras que los liberales prefieren el clasicismo. El defiende, en cambio, un romanticismo de influencia italiana, marcado por el racionalismo filosófico, que se caracteriza por su espíritu moderno y liberal.

Con el Prólogo de Cromwell (1827) de Víctor Hugo el romanticismo 
francés encuentra su manifiesto crítico. Su autor intenta elaborar una teoría histórico-literaria y concibe la historia de la poesía como sucesión de lírica, épica y dramática. El aspecto más interesante de su teoría es su noción de lo grotesco opuesto a lo sublime. Concibe el arte como una actividad globalizadora, capaz de incluir todas las facetas de la humanidad y de la naturaleza, desde lo grotesco a lo sublime. Víctor Hugo no fue un gran crítico, pero sus teorías gozaron de extraordinaria repercusión. Posteriormente insistió en la función social de la literatura y destacó la importante misión del poeta, en el que veía una especie de profeta de la humanidad. Adoptó la concepción místico-simbólica de la poesía, de origen alemán.

Además de la batalla de los nuevos autores en defensa del romanticismo, caracteriza la primera mitad del siglo XIX francés la aparición de la historia literaria, elaborada en Alemania años antes, y las discusiones en torno a la finalidad del arte.

El ginebrino Jean-Charles Léonard Simonde de Sismondi (1773-1842), amigo de Mme de Staël, crea la historia literaria en Francia con su obra De la littérature du Midi de l'Europe (4 vols., 1813). Claude Fauriel (17721844) y su discípulo Jean Jacques Ampère (1800-1864) crean la historia de la literatura medieval. La historia literaria cobra mayor desarrollo con Abel François Villemain (1790-1870). Se interesa por las relaciones de la literatura con la sociedad. Sus preferencias iban claramente por el neoclasicismo. Pero sólo con Philarète Chasles (1798-1873) el cuadro de la historiografia literaria francesa se enriquece con datos abundantes procedentes de la historia literaria de otros paises.

Los historiadores de la literatura y los críticos se inclinan por la época clásica y condenan la literatura de su tiempo. La tendencia es particularmente evidente en el periodista y crítico Gustave Planche (1808-1857), enemigo acérrimo de Sainte-Beuve, en Saint-Marc Girardin (1801-1873) y en Désiré Nisard (1806-1888). Nisard elaboraría la primera historia de la literatura francesa completa. Intenta convertir la crítica en ciencia, explicando la grandeza de las obras literarias a partir de tres variantes: el espíritu humano universal, el genio particular de cada país y el genio de la lengua francesa.

La enseñanza de la historia literaria presenta en general un tono didáctico oficialista; frente a esto, la aparición del primer socialismo incita a exaltar la función social del poeta. Como reacción contra estas dos tendencias, Théophile Gautier (1811-1872) replica, en el Prólogo a su obra Mlle de Maupin (1834), proclamando la total autonomia de lo bello y exaltando la teoría del arte por el arte. Al mismo tiempo rompe con la tendencia más general de la crítica a ensalzar el clasicismo y exalta a los poetas no clásicos de la primera mitad del siglo XVII, olvidados hasta la época, en Les Grotesques (1844).

El crítico más importante de los años centrales del siglo es, sin duda, Charles-Augustin Sainte-Beuve (1804-1869). Deseaba ser poeta y novelista: 
sus fracasos lo obligaron a dedicar la mayor parte de su tiempo a la crítica literaria. Compuso una obra vastísima, que gozó de gran influencia, en parte debido a su buen juicio y a la amenidad de su estilo. Pese a ello, erró profundamente con sus contemporáneos: fue incapaz de valorar adecuadamente a Stendhal, Balzac y Baudelaire. No mostró gran interés por la teoría literaria, ni siquiera por el análisis de la obra. Convirtió la crítica en una galería de semblanzas literarias, donde la obra se resolvía en la biografia de su autor. Años más tarde Proust se alzaría contra él y le reprocharía su incapacidad para comprender al artista.

Intenta desenmascarar al autor detrás de su obra. Pretende situar a los autores dentro de la historia literaria, trazando panoramas históricos, comparando unas obras con otras. Concibe la crítica como una actividad artística pero sobre todo como actividad enjuiciadora de las obras literarias. Admira la actividad critica de Boileau y aprecia los autores que él alababa: sus preferencias se dirigen al siglo XVII francés, a la época clásica, y en cambio siente poco interés por la Edad Media y no comprende a Ronsard. Con el tiempo se volvió más duro con sus contemporáneos románticos, aunque influyeron en estas actitudes motivos personales y no sólo el gusto literario.

Carece de gran profundidad teórica. Es ante todo un ensayista; su contribución teórica es reducida y uno de sus mayores logros es el interés que logró suscitar por la crítica literaria.

\subsection{Italia}

En Italia el romanticismo presenta peculiares connotaciones políticas. En $1816 \mathrm{Mme}$ de Staël publica un artículo en el que recomienda a los italianos abandonar el decadente neoclasicismo para interesarse por Shakespeare y los poetas alemanes e italianos. En la polémica suscitada por esta obra, un grupo de jóvenes milaneses se alínea con las posiciones de la autora y en el periódico Il Conciliatore (1818-1819), muy pronto suprimido por la policía austriaca, defiende posturas que buscan no sólo la renovación de las artes italianas sino también de la vida del pais. Desde posiciones contrarias, defiende durante un tiempo Manzoni el romanticismo, viendo en esta corriente artística la manifestación de una mayor verdad histórica y sobre todo de la verdad cristiana.

El grupo romántico careció de fuerza y fue atacado por los poetas que más exactamente encarnan el ideal romántico: Foscolo y Leopardi. Ugo Foscolo (1778-1827) comparte con los románticos europeos la creencia en el poder de la fantasía y la insistencia en el carácter individual y personal de la obra de arte pero ataca las teorías de Manzoni. También Giacomo Leopardi (1798-1837) atacó a los románticos. Piensa que la civilización ha 
cegado las fuentes de la imaginación y de la gran poesía; la poesía es esencialmente sentimiento y lirismo. La lírica es la poesía por excelencia. Sólo le interesan los autores antiguos, Dante y los poetas italianos del Renacimiento pero no sus contemporáneos. Su obra quedó sin influencia en su momento.

La crítica se divide en dos bandos claramente delimitados y las nociones estéticas se mezclan con elementos políticos o religiosos. Por un lado, la mayoría de los críticos de signo católico-conservador ven en Dante al máximo poeta italiano, por su carácter católico (Vicenzo Gioberti, 1801-1852; Niccolò Tommaseo, 1802-1874); frente a ellos se alza la tendencia laicoliberal o progresista (Giuseppe Mazzini, 1805-1872). Se desarrolla la historia literaria: Paolo Emiliani Giudici (1812-1872) compone su Storia delle belle lettere in Italia (1845) y Luigi Settembrini (1813-1872) sus Lezioni di Letteratura italiana (1866-1872).

\subsection{España}

Durante las primeras décadas del siglo XIX siguieron publicándose tratados de indole neoclásica (Arte de hablar en prosa y verso, 1820, de José Gómez Hermosilla; Poética, 1827, de Martínez de la Rosa). Se continúa, además, la tarea emprendida en el siglo anterior de elaborar la historia de la literatura española y estudiar las letras medievales y del Siglo de Oro: en 1846 se inicia la publicación de los volúmenes de la Biblioteca de Autores Españoles.

El romanticismo no supuso en España la aparición de grandes contribuciones teóricas. En la controversia del nuevo movimiento se manejaron conceptos elaborados por los críticos extranjeros.

La polémica sobre el romanticismo se suscitó a raíz de la publicación por José Joaquín de Mora (1763-1864), en el Mercurio Gaditano, en 1814, de una crítica de las reflexiones de A.W. Schlegel aparecidas poco antes en la misma revista. Defiende las «reglas eternas del gusto», ataca la "corrupción de la literatura moderna y extranjera» y las alabanzas de Schlegel a Calderón como prototipo del poeta del mundo cristiano. Replicó Nicolás Böhl de Faber (1770-1864), alemán establecido en Cádiz, defendiendo los puntos de vista de Schlegel. De este modo, se identificó el romanticismo con la poesía cristiana - frente al clasicismo que imita a la antigüedad pagana-, se ensalzó a Calderón como escritor romántico y se afirmó la pervivencia del espíritu romántico - vinculado al cristianismo- desde la Edad Media. La polémica tomó un tinte político: el liberal Mora veía en las teorías de Schlegel y en los ejemplos alemanes e ingleses una fuente de corrupción del gusto español, mientras que el monárquico conservador Böhl defendía a un movimiento al que consideraba la respuesta a la nueva sensibilidad 
aportada por el cristianismo, movimiento que hundía sus raices en la Edad Media monárquica y caballeresca. Por esos años, el término más usual para designar esta nueva tendencia era romancesco. Sólo unos años después (1823) se impuso romántico con un artículo de Luigi Monteggia: de tono moderado y conciliador, defendía que los románticos imitaban a los antiguos de modo más filosófico que los clásicos pues, lejos de quedarse en los elementos secundarios, intentaban crear un arte conforme a su época, como habían hecho los antiguos. Agustín Durán publicó, en 1828, el más importante escrito de la época sobre la cuestión: su Discurso sobre el influjo que ha tenido la critica moderna en la decadencia del teatro antiguo español... Como Schlegel, Bölh o López Soler cree que el romanticismo está vinculado al cristianismo. Lamenta la ruina del teatro español del Siglo de Oro, que atribuye a la influencia francesa. Piensa que los neoclásicos no supieron comprender que en España las reglas no se habían imitado, no por ignorancia, sino porque no se adaptaban al espíritu español, ya que el teatro es distinto en cada país, pues es la expresión poética de sus necesidades morales y de sus gustos. Aunque Alberto Lista criticaba las obras románticas por sus efectos morales, imperaba la concepción del romanticismo como arte de las naciones cristianas. En 1854 Jerónimo Borao veía como principios fundamentales del movimiento el nacionalismo, la libertad y el cristianismo. Se consideraba como una corriente nacida en la Edad Media, a la que se debían las obras maestras del teatro español e inglés. Se entendía como movimiento general, opuesto a clasicismo, y no como movimiento histórico de la época. Sólo Alcalá Galiano, en el Prólogo al Moro expósito (1834), veía en el romanticismo no tanto el arte cristiano como un arte más adecuado para ciertos países: en Alemania el romanticismo es tan castizo como lo es el clasicismo en Italia. Así, su prototipo de poetas románticos no son Dante, Shakespeare y Calderón sino Scott y Byron. Se abría camino la concepción del romanticismo como movimiento histórico y no como tendencia general opuesta al clasicismo.

\subsection{Rusia}

Durante la primera mitad del siglo, Visarion Bielinski (1811-1848) es el principal crítico ruso. Sus ideas proceden de la crítica romántica alemana. Como ellos, concibe la literatura como expresión del pueblo que la crea y ve en la obra un todo orgánico, pero no piensa que la literatura rusa antigua pueda ser modelo para la literatura en sus días. En sus últimos años se inclinó hacia cierto radicalismo político. Creyó en el progreso, y buscó en la literatura la manifestación de un propósito social, aspecto que destacaría en él la crítica soviética posterior. 